\title{
Experimental Investigation on Flame Characterization and Temperature Profile of Single/Multiple Pool Fire in Cross Wind
}

\author{
CHEN Zhen ${ }^{1,2}$, WEI Xiaolin ${ }^{2 *}$, LI Teng ${ }^{2}$
}

1. Key Laboratory for Thermal Science and Power Engineering of Ministry of Education, Department of Energy and Power Engineering, Tsinghua University, Beijing 100084, China

2. State Key Laboratory of High Temperature Gas Dynamics, Institute of Mechanics, Chinese Academy of Sciences, Beijing 100190, China

(C) Science Press, Institute of Engineering Thermophysics, CAS and Springer-Verlag GmbH Germany, part of Springer Nature 2020

\begin{abstract}
An experimental study was carried out to investigate the flame characterization and temperature profile for single and multiple pool fire with the influence of cross wind. There were 13 test cases in total, categorized into circle and rectangle fuel pans, with diameter (or equivalent diameter) ranged from $50 \mathrm{~mm}$ to $300 \mathrm{~mm}$. Kerosene was used for the fuel of pool fire. Some K-type thermocouples were arranged around the flame to monitor the flame temperature, while the flame tilt angle was measured based on the photograph of flame for different case. Firstly, it can be found that there are three phases, including preheating, steady burning and extinguishing phase, during the flame evolution. The maximum temperature near the fuel surface is $\sim 1040 \mathrm{~K}$, which is higher than that of flame plume $(\sim 600 \mathrm{~K})$, in the steady burning phase of circle single pool fire $(D=300$ $\mathrm{mm}$ ), while the average burning rate is $\sim 1.525 \mathrm{~g} / \mathrm{s}$. In addition, the burning rates of all cases were measured and compared with the current predicted method. Typically, the flame morphology of single/multiple pool fire at different cross wind speed (ranging from 0 to $3.5 \mathrm{~m} / \mathrm{s}$ ) was analyzed, and it is found that the results for single pool fire agree with Thomas model and AGA model well, which are not suitable for multiple pool fire. Finally, the temperature profile of different case was measured with various wind speed.
\end{abstract}

Keywords: pool fire, temperature profile, flame characteristic, kerosene, cross wind

\section{Introduction}

The storage and transportation of hydrocarbon fuels, e.g. crude oil, LNG, kerosene, is very important for the processing and production in energy and chemical industries [1, 2], as well as the national energy security [3]. However, these fuels belong to flammable and explosive materials, which are easy to form fire and cause explosion accident, such as pool fire [4-6], vapor cloud explosion (VCE) [7, 8], boiling liquid expanding vapor explosion (BLEVE) [8], etc. Once the hazardous accident goes out of control, the domino effect would develop in the chemical industry, which can bring about huge economic losses and casualties [9, 10]. Pool fire is one of the most common accident forms in the storage and transportation of hydrocarbon fuels [3, 4]. The development process of pool fire accidents have a crucial influence on fire rescue, including fire prevention and extinguishing, safety evacuation $[3,11,12]$. Meanwhile, it is an important fundamental topic in combustion and 
flame field [13-15], which has been studied for decades.

As shown in Fig. 1, pool fire in still air is driven mainly by buoyance (a), while it is determined by the coupling of buoyancy and wind (b) in wind [14]. Firstly, the burning rate (mass transfer) is related to heat feedback mechanism (heat transfer) from the flame to the fuel surface. In still air, the heat feedback mechanism includes conduction, convection, and radiation, depending on the pool size $[16,17]$. In wind, the flame tilts and the burning rate would be enhanced. As a result, the behaviors of pool fire are much more complicated [14] in wind, the temperature and radiation profile of which would change with the flame characteristics.

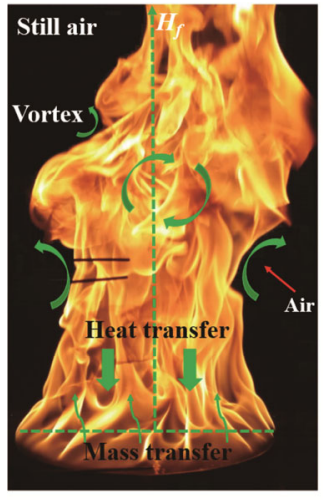

(a)

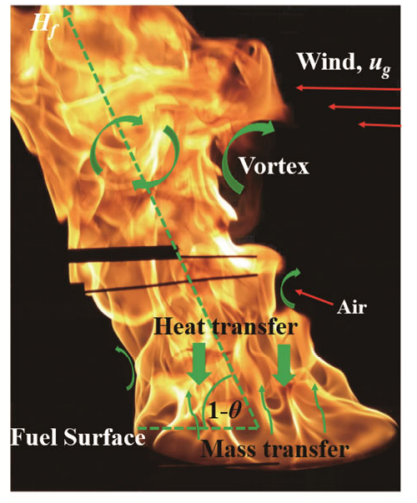

(b)
Fig. 1 Characteristic of pool fire in still air (a) and in wind (b)

In general, there are many research achievements on pool fires, focusing on burning rate [13-17], flame geometry $[15,17-21]$, temperature profile $[15,22,23]$, and soot and radiation [20,21, 23, 24], etc.

For the pool fire driven only by buoyancy in still air, abundant studies have been conducted on the flame characterization for pool fire with different scales [25]. It is well understood that combustion characteristics of pool fire in still air are scale-dependent [13]. Heskestad [26] and Moorhouse [27] proposed the basic correlations for flame height of axisymmetric sources based on different experimental measurements.

Most of the researches about the pool fire driven by buoyancy and wind in cross wind were carried out in recent years. Based on previous results, many improvement studies have been carried out by taking different factors into account to develop more precise predicted model. $\mathrm{Hu}$ [28] quantified experimentally the pool fire flame tilt angle in a wind and measured the mass burning rate simultaneously for the pool dimension ranging from 10 to $25 \mathrm{~cm}$ in diameter. Lam et al. [29, 30] measured the flame drag, flame tilt and length, based on a $2 \mathrm{~m}$ diameter pool fire with aviation fuel. They proposed the semi-empirical correlations in wind. Muñoz et al. [21] measured the radiation intensity with different pool sizes and flame positions by infrared camera. $\mathrm{Hu}$ [31] investigated the radiation feedback of flame on square pool with dimensions of $10-25 \mathrm{~cm}$ in cross wind.

It should be noted that the pool fire can be classified into two categories [4]: single pool fire and multiple pool fire (two or more fires burning simultaneously). In fact, once pool fire takes place in chemical industrial park, it is easy to develop to multiple pool fire, which is more hazardous. However, the majority of current work was focusing on single pool fire, while the research on the multiple pool fire in wind is relatively limited. Especially, the temperature profile of multiple pool fire in cross wind is rarely reported in literature, which has a significant effect on accident spread and fire controlling. Planas-Cuchi [32] measured the temperature distribution around the flame with hexane $\left(4 \mathrm{~m}^{2}\right)$ and kerosene $\left(12 \mathrm{~m}^{2}\right)$ multiple pool fire, without taking wind speed into consideration. Fukuda [33] and Delichatsios [34] have carried out the research on multiple pool fire, but focused on burning rate, flame length, and air entrainment, without taking temperature profiles into consideration. Only Vasanth [35] obtained the temperature results of multiple pool fire by numerical method, but the study lacks experimental verification.

As a result, this work focuses on combustion process and flame characteristic of multiple pool fire in cross wind, including burning rate, flame tilt angle, temperature profile, with different pool dimensions.

\section{Experimental Setup}

This work is conducted in a wind tunnel as shown in Fig. 2. The total length of the wind tunnel is $4500 \mathrm{~mm}$, with the sectional dimension of $1200 \mathrm{~mm} \times 1200 \mathrm{~mm}$. The air flow is driven by a fan (230W, Wahson, China), controlled by a frequency changer. In order to make the air flow uniform in the wind tunnel, three pieces of wire mesh is set as wind distributor. At the upstream of the tunnel, the cross wind speed is monitored by hot-wire anemometers (Testo 425, with accuracy $0.01 \mathrm{~m} / \mathrm{s}$, Germany). Two fuel pans, which are made of stainless steel with $2 \mathrm{~mm}$ thickness, are placed on electronic balances (Yingheng, with accuracy $0.1 \mathrm{~g}$, China). The combustion process of pool fire is recorded by a digital camera. Kerosene is used as fuel in this experiment. According to the burning rate of kerosene and previous work [31], the fuels thickness is set at $2 \mathrm{~cm}$ to maintain combustion time no less than $10 \mathrm{~min}$. The pool fire is ignited with an electronic igniter. Each experimental case has been repeated more than one time to reduce random error.

In order to investigate the effect of pool shape and size, various fuel pans are designed, as shown in Table 1. 
There are 13 fuel pans with different scale in total, including single pool fire and multiple pool fire on both circle fuel pan and rectangle fuel pan. The wind speed would be adjusted from $v_{\mathrm{g}}=0$ (in still air), after igniting the pool fire. For circle fuel pan, the diameter $(D)$ ranges from $5 \mathrm{~cm}$ to $30 \mathrm{~cm}$, while for rectangle pan the size ranges from $100 \mathrm{~mm} \times 100 \mathrm{~mm}$ to $300 \mathrm{~mm} \times 300 \mathrm{~mm}$. The distance $(d)$ between two fuel pans in the multiple pool fire cases is related to the pool size, as listed in Table 1.

A series of K-style thermocouples are arranged above the fuel pans, as shown in Fig. 3. The positions of thermocouples vary with different cases. For circle single pool fire, three thermocouples are deployed right above the top surface of fuel pan. Another three thermocouples are set above the previous ones, with the distance of $l$ (as listed in Table 1) for different cases. For circle multiple pool fire, eight thermocouples in total on the pan with different elevation are arranged in the center or at the edge of the pan. Similarly, the layout of thermocouples for various rectangle pool fire cases are set as Fig. 3.

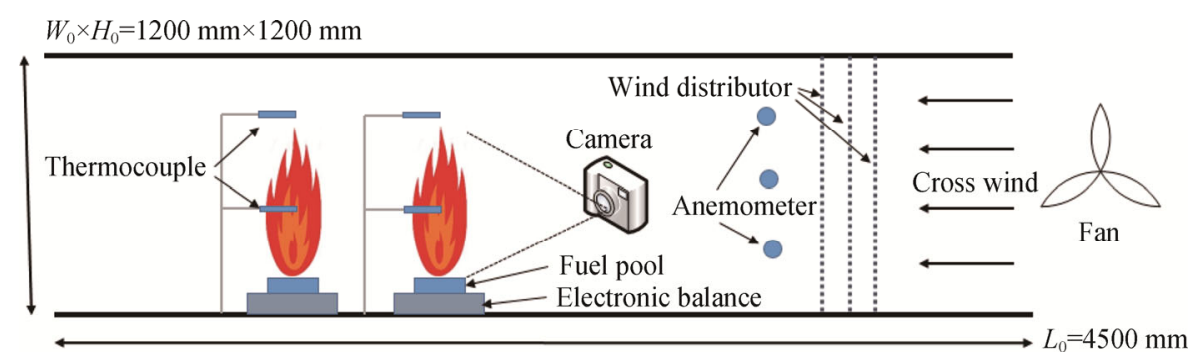

Fig. 2 Experimental setup of single/multiple pool fire

Table 1 Geometrical parameter of various cases

\begin{tabular}{|c|c|c|c|c|c|c|c|c|c|}
\hline NO. & $\begin{array}{c}\text { Pool scale/ } \\
\mathrm{mm}\end{array}$ & Pool type & $l / \mathrm{mm}$ & $d / \mathrm{mm}$ & NO. & $\begin{array}{c}\text { Pool scale/ } \\
\mathrm{mm}\end{array}$ & Pool type & $l / \mathrm{mm}$ & $d / \mathrm{mm}$ \\
\hline Case-1 & $D=200$ & Circle, Single & 150 & - & Case- 8 & $200 \times 300$ & Rectangle, Single & 150 & - \\
\hline Case-2 & $D=250$ & Circle, Single & 200 & - & Case-9 & $300 \times 300$ & Rectangle, Single & 150 & - \\
\hline Case-3 & $D=300$ & Circle, Single & 250 & - & Case-10 & $100 \times 100$ & Rectangle, Multiple & 150 & 50 \\
\hline Case-4 & $D=50$ & Circle, Multiple & 50 & 25 & Case-11 & $100 \times 200$ & Rectangle, Multiple & 150 & 80 \\
\hline Case-5 & $D=100$ & Circle, Multiple & 100 & 50 & Case-12 & $100 \times 300$ & Rectangle, Multiple & 150 & 100 \\
\hline Case-6 & $D=200$ & Circle, Multiple & 150 & 100 & Case-13 & $200 \times 200$ & Rectangle, Multiple & 150 & 100 \\
\hline Case-7 & $150 \times 300$ & Rectangle, Single & 150 & - & & & & & \\
\hline
\end{tabular}

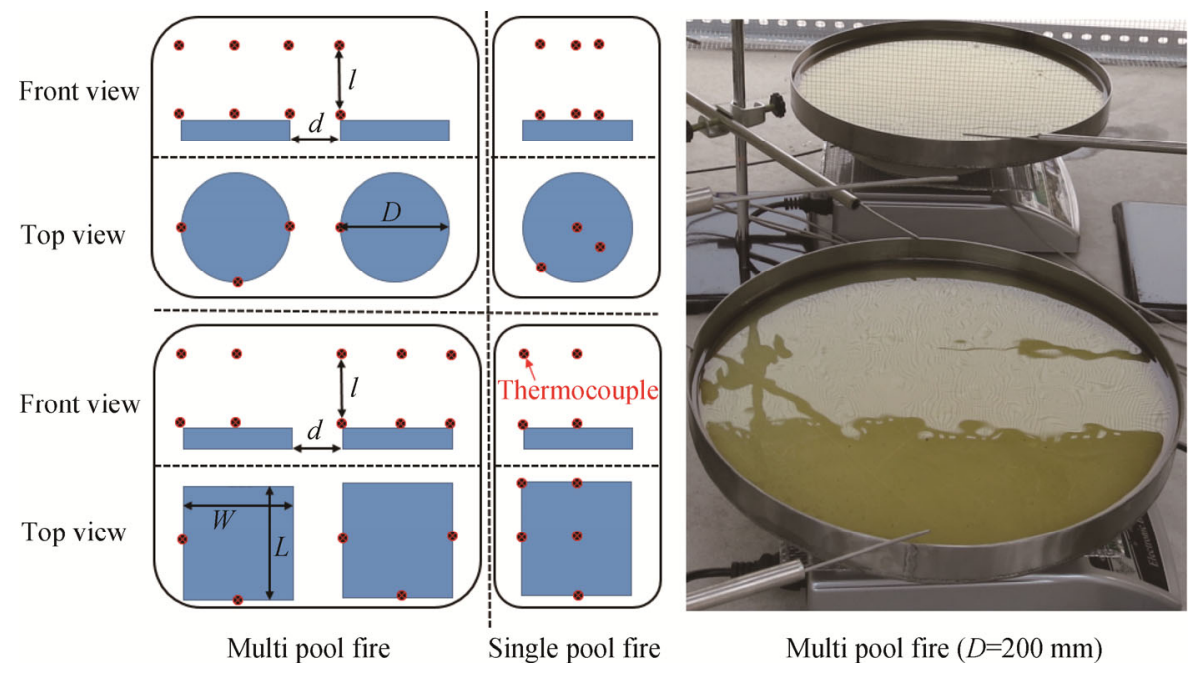

Fig. 3 Layout of thermocouples for various cases 


\section{Results and Discussion}

\subsection{Flame evolution and burning rate}

Taking the combustion process of Case-3 ( $D=300 \mathrm{~mm}$, single pool fire, in still air) for example, the evolution of flame shape and the temperature profiles in the center of fuel pan at different elevation are shown in Fig. 4(a) and (b), respectively. After the fuel was ignited for $t \approx 40 \mathrm{~s}$, the flame starts to grow and the temperature increases gradually. According to the flame temperature variation, the combustion process could be divided into three phases: preheating phase, steady burning phase, and extinguishing phase. In preheating phase, the flame height keeps growing and the flame temperature increases gradually to approximately $1040 \mathrm{~K}$. The evaporation rate increases with the heat release rate of combustion increases. The heat flux feedback from flame to fuel surface is determined by conduction, convection and radiation $[17,36]$. Starting from $t \approx 144 \mathrm{~s}$, the flame turns into a fully turbulent regime from the initial laminar regime, and the combustion goes into steady burning phase. It can be found there is a strong fluctuation for the fire even in still air, which may be caused by air entrainment during the combustion process. In addition, it can be observed that the flame height is about $400 \mathrm{~mm}$. As the fuel exhausts, the flame temperature decreases quickly until the extinguishing, which lasts about $50 \mathrm{~s}$. The average burning rate is estimated to be $1.525 \mathrm{~g} / \mathrm{s}$, from ignition to extinguishing.

According to a previous study, the pool diameter $(D)$ is one of the most important factors for burning rate in still air [25]. For circle pool fire, the pool diameter is equal to the fuel pan scale, while the equivalent diameter of rectangle pool could be calculated by Eq. (1):

$$
D=2 \cdot \sqrt{\frac{S_{\text {pool }}}{\pi}}=2 \cdot \sqrt{\frac{L \times W}{\pi}}
$$

where, $S_{\text {pool }}$ is the area of rectangle pool; $L$ and $W$ is the length and width, respectively.

For the pool fire in still air, an empirical expression proposed by Babrauskas [37] is widely used for predicting the burning rate, which is controlled by convection or radiation feedback:

$$
\dot{m}^{\prime \prime}=\dot{m}_{\infty}^{\prime \prime}\left(1-e^{-k \beta D}\right)
$$

where, $\dot{m}^{\prime \prime}$ is the mass burning rate per unit area, $\mathrm{g} /\left(\mathrm{s} \cdot \mathrm{m}^{2}\right) ; \quad \dot{m}_{\infty}^{\prime \prime} \quad$ is the infinite-diameter pool mass burning

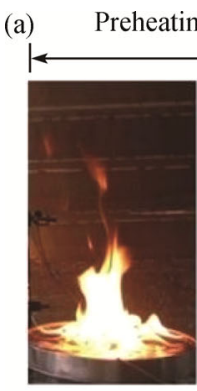

$t=68 \mathrm{~s}$

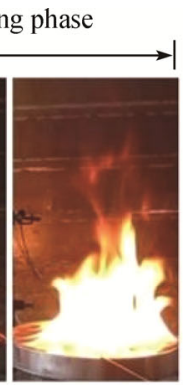

$93 \mathrm{~s}$

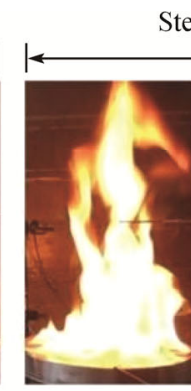

$144 \mathrm{~s}$
Steady burning phase

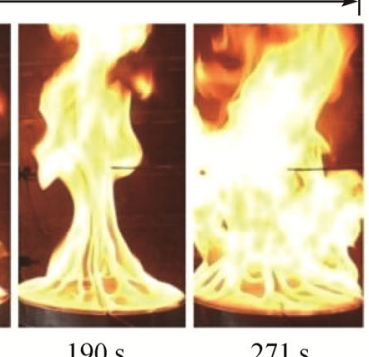

Extinguishing phase

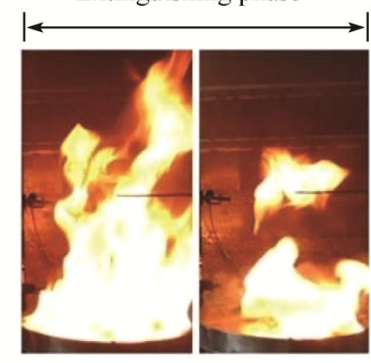

$285 \mathrm{~s}$

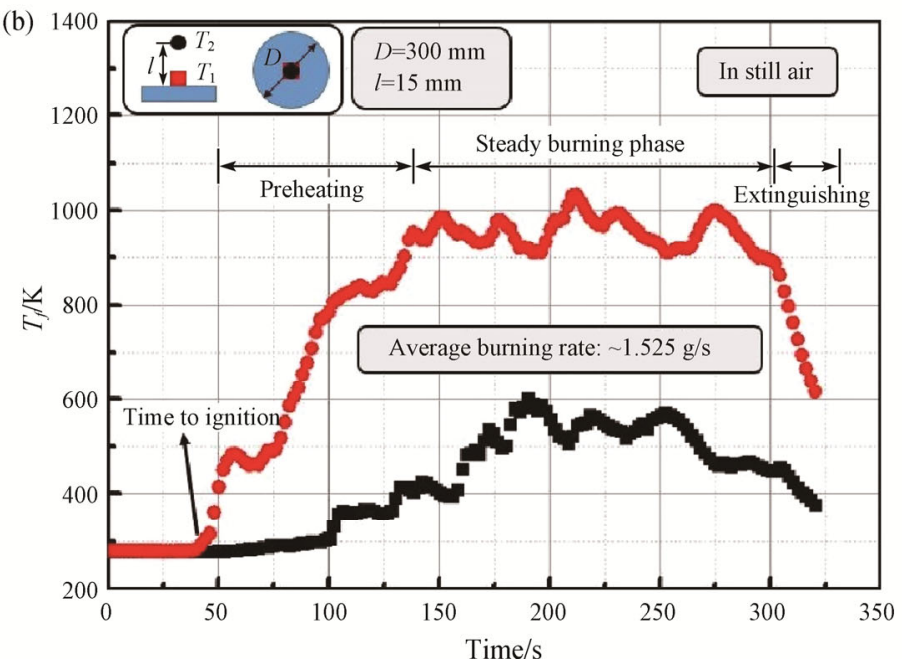

Fig. 4 Flame shape (a) and temperature profile (b) of single pool fire $(D=300 \mathrm{~mm})$ 
rate, $\mathrm{g} /\left(\mathrm{s} \cdot \mathrm{m}^{2}\right) ; D$ is the diameter of fuel pool, $\mathrm{m} ; k$ and $\beta$ are extinction coefficient $\left(\mathrm{m}^{-1}\right)$ and mean beam length corrector, respectively. The parameters $\dot{m}_{\infty}^{\prime \prime}, k$ and $\beta$ are obtained from Babrauskas's work [37].

The experimental and calculation results of the burning rate for all pool fire cases in still air are shown in Fig. 5, at cross wind speed $u=1 \mathrm{~m} / \mathrm{s}$. The experimental results of single pool fire agree well with the prediction (Case-1, Case-2, Case-3, Case-7, Case-8 and Case-9). However, for multiple pool fire cases, significant differences exist between the experimental and calculation results (Case-4, Case-5, Case-6, Case-10, Case-11, Case-12 and Case-13). In multiple pool fire cases, the fuel in one pool could be heated by the flame of neighboring pool fire. Thus the average burning rate is most likely to be promoted compared with the single pool fire. In addition, as the pool size decreases in multiple pool fire case, the deviation of the calculated results increases. For instance, the measured and predicted burning rate for left pool in Case-4 is $\sim 0.191$ $\mathrm{g} /\left(\mathrm{s} \cdot \mathrm{m}^{2}\right)$ and $\sim 0.006 \mathrm{~g} /\left(\mathrm{s} \cdot \mathrm{m}^{2}\right)$, respectively. In addition, it could be found that burning rate of the left pool is greater than the right for all multiple pool fires cases. It was because the average burning rate was measured with cross wind, approximately $1 \mathrm{~m} / \mathrm{s}$, and the left pan located at the downwind. Therefore, the left pan would receive more heat feedback from the sloping flame.

As mentioned above, the prediction model in Eq. (2) is proposed based on the experiments of relatively large pool fire $(D>0.1 \mathrm{~m})$, the heat feedback of which is mainly controlled by radiation and convection. However, the pool size in Case-4 is $50 \mathrm{~mm}$, and little or no flame fluctuation was observed, so it may belong to laminar flame and is mainly controlled by conduction heat feedback mechanism. As a result, Eq. (2) is not suitable for Case-4 as well as Case-10 with equivalent diameter of $113 \mathrm{~mm}$, for which the heat conduction has a significant impact.

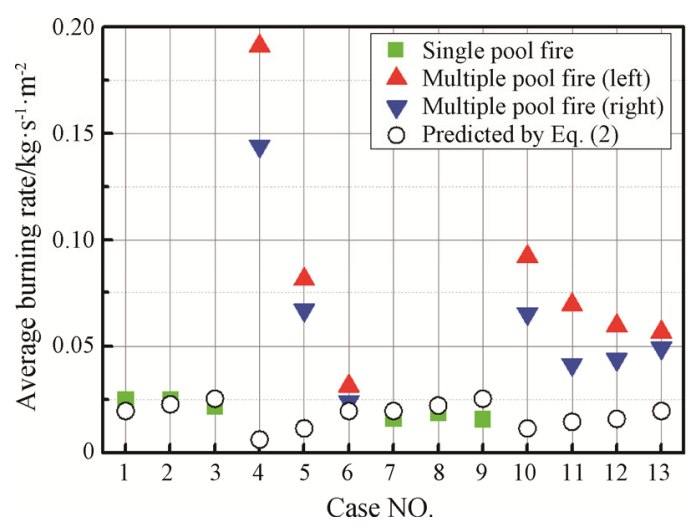

Fig. 5 The average burning rate of different pool fire

\subsection{Flame tilt angle}

The tilt of flame is one of the most remarkable morphological characterizations of pool fire in wind. Usually, pool fire takes place in open environment, which is easy to be affected by wind. As aforementioned, the heat feedback to fuel surface will change and the burning rate will increase in wind. In addition, the temperature profile around the pool fire, the effect area of the pool fire on surroundings such as neighboring fuel tank and firefighters will also change. As a result, it is very important to investigate the flame tilt angle and temperature profile (in Section 3.3) of pool fire in wind.

The flame morphology of single/multiple pool fire at different cross wind speed (ranging from 0 to $3.5 \mathrm{~m} / \mathrm{s}$ ) is shown in Fig. 6. Case-3 and Case-12 are selected as the representative for single and multiple pool fire, respectively.

The relationship between the measured flame tilt angle $(\theta)$ and the cross wind speed for Cass-2, Case-3, Case-10 and Case-12 is shown in Fig. 7. The flame tilt angle increases quickly as the wind speed increases from $\sim 0.5$ to $\sim 1.5 \mathrm{~m} / \mathrm{s}$. Keeping increasing the wind speed to $\sim 3.5$ $\mathrm{m} / \mathrm{s}$, the tilt angle increases slowly and approaches $90^{\circ}$ gradually. For circle single pool fire, the flame tilt angle with larger pool size $(D=300 \mathrm{~mm})$ is smaller than that with small pool size $(D=250 \mathrm{~mm})$ at the same cross wind speed. Similar result is found for rectangle pool fire, i.e. the flame tilt angle of left pool in Case-10 (100 mm $\times 100$ $\mathrm{mm})$ and Case- $12(100 \mathrm{~mm} \times 300 \mathrm{~mm})$ is approximately $72^{\circ}$ and $68^{\circ}$, respectively, at the wind speed of $\sim 1.5 \mathrm{~m} / \mathrm{s}$. In addition, the flame tilt angle of left pool is larger than that of right pool for multiple pool fire, because the left pool is located downstream in the wind tunnel.

According to the previous work, several different predicted models about flame tilt angle have been proposed [28]. Thomas model [38] and American Gas Association (AGA) model [39] are the two frequentlyused models. Thomas model, which is expressed as Eq. (3), was established based on wood crib fire results [38]. Thomas model was then further developed by American Gas Association (AGA) [39], which is shown as Eq. (4).

$$
\begin{gathered}
\cos (\theta)=0.7 \cdot\left(u^{*}\right)^{-0.49} \\
\cos (\theta)= \begin{cases}1 & \left(u^{*} \leq 1\right) \\
1 /\left(u^{*}\right)^{0.5} & \left(u^{*}>1\right)\end{cases} \\
u^{*}=\frac{u}{\left(g \dot{m}^{\prime \prime} D / \rho_{\infty}\right)^{1 / 3}}
\end{gathered}
$$

where, $\theta$ is the flame tilting angle; $u^{*}$ is the dimensionless cross wind speed, $\mathrm{m} / \mathrm{s} ; g$ is gravitational acceleration, 9.8 $\mathrm{m} / \mathrm{s}^{2} ; \rho_{\infty}$ is air density, $\mathrm{kg} / \mathrm{m}^{3}$.

These measured tilt angles for Cass-2, Case-3, Case-10 and Case-12 are compared with the calculation 
(a)

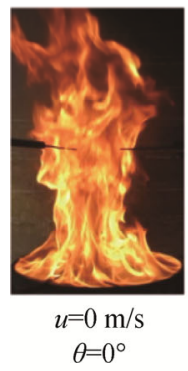

(b)

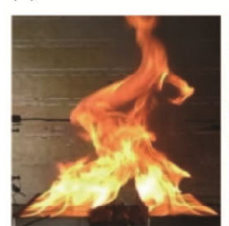

$u=0 \mathrm{~m} / \mathrm{s}$

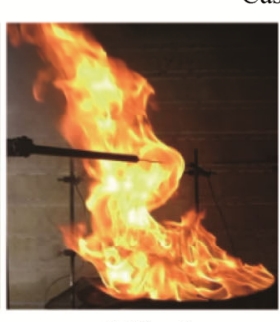

$u=0.72 \mathrm{~m} / \mathrm{s}$ $\theta=30.2^{\circ}$

Case- 3 ( $D=300 \mathrm{~mm}$, single pool fire)

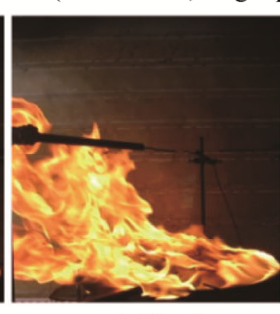

$u=1.45 \mathrm{~m} / \mathrm{s}$ $\theta=62.7^{\circ}$

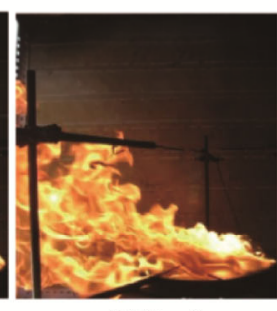

$u=2.73 \mathrm{~m} / \mathrm{s}$ $\theta=75.4^{\circ}$

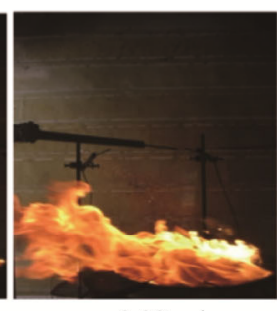

$u=3.39 \mathrm{~m} / \mathrm{s}$ $\theta=78.3^{\circ}$

Case- $12(L \times W=100 \times 300 \mathrm{~mm}$, multiple pool fire $)$

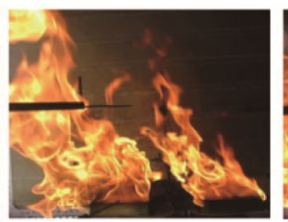

$u=0.65 \mathrm{~m} / \mathrm{s}$

$\theta_{\text {Leff }}=32.3^{\circ}$

$\theta_{\text {Righ }}=37.3^{\circ}$

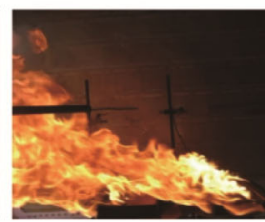

$u=1.57 \mathrm{~m} / \mathrm{s}$

$\theta_{\text {Left }}=63.4^{\circ}$

$\theta_{\text {Right }}=68.7^{\circ}$

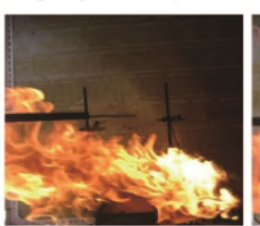

$u=2.64 \mathrm{~m} / \mathrm{s}$

$\theta_{\text {Left }}=74.4^{\circ}$

$\theta_{\text {Right }}=79.5^{\circ}$

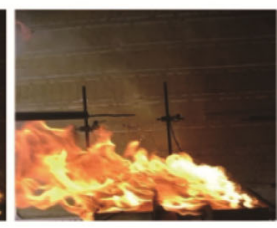

$u=3.17 \mathrm{~m} / \mathrm{s}$

$\theta_{\text {Left }}=80.2^{\circ}$

$\theta_{\text {Right }}=85.3^{\circ}$

Fig. 6 Flame shape of single/multiple pool fire in wind (Case-3 and Case-12)

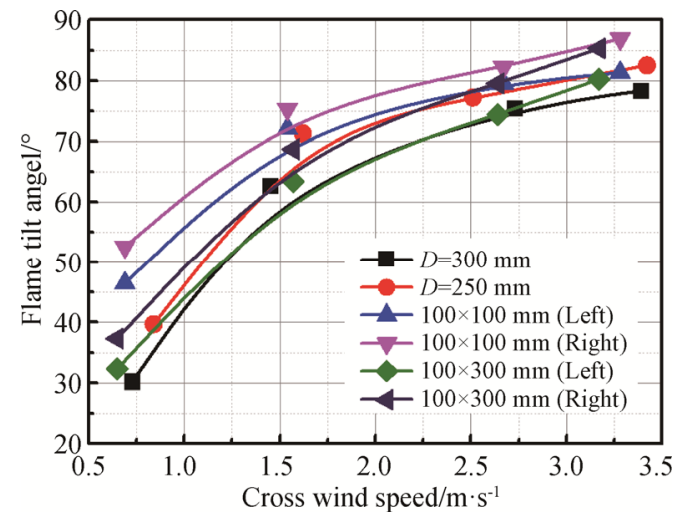

Fig. 7 The Flame tilting angle at various wind speed

results by using the above two prediction models, as shown in Fig. 8(a)-(f). Generally, the variation trend of the measured values is in consistent with that of the predicted values, but with a relatively large deviation. This is possibe because the two models were not developed based on hydrocarbon pool fire. Comparatively, the predicted values by Thomas model are more close to the measured values. As to single pool fire (Fig. 8(a) and (b)), the experimental results are more close to the Thomas model when $\left(u^{*}\right)^{-0.5}<0.5$.

\subsection{Temperature profile}

The average temperatures of the measured points during $\sim 5 \mathrm{~s}$ are calculated, when the cross wind speed and flame tilt angle are steady at some value. The relationship of average temperature and flame tilt angle for different cases is shown in Fig. 9.

For single circle pool fire (Fig. 9(a) and 9(c)), the temperatures of two point $\left(T_{1}\right.$ and $\left.T_{2}\right)$ with different elevation in the center of fuel pool are measured, while the measured point is at the edge of the fuel pool for multiple pool fire (Fig. 9(b) and (d)). According to Fig. 9(a), it can be found that $T_{2}$ decreases as the angle increases, which is caused by the blown flame. In contrast, $T_{1}$ increases as the angle increases. There are two possible reasons: firstly, the burning rate and heat release rate increase at larger cross wind speed, which can promote the flame temperature above the fuel surface; secondly, the tilt angle decreases the distance between the fire and $T_{1}$ measured point, and is conductive to heat transfer from flame to fuel surface. In addition, it can be found that the average temperature is in the order of: Case-3 $>$ Case- $2>$ Case- 1 . This indicates that the larger the pool size, the higher the temperature at same flame tilt angle.

For Case-4 and Case-5 (see Fig. 9(b)), it can be observed that the temperature of $T_{1}$ decreases with increasing the tilt angle after $\theta>80^{\circ}$, which is different from other circle pool fire. The possible reason may be that the small pool size (less or equal to $100 \mathrm{~mm}$ ) was used in Case-4 and Case-5. A laminar flame could probably develope in these cases, which have different performance at higher cross wind. The result is similar to the circle multiple pool fire. In addition, due to the blowing flame, the temperature at the edge of right fuel pan ( $T_{1}$ point) for multiple pool fire (Case-4, Case- 5 and Case-6) is higher than that of center point for single pool fire (Case-1, Case-2 and Case-3).

For rectangle single/multiple pool fire, the measurement positions of temperature are the same as that of circle pool fire. It can be found that the temperatures of 


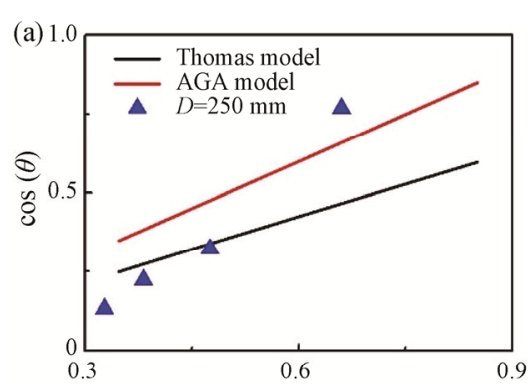

$\left(u^{*}\right)^{-0.5}$

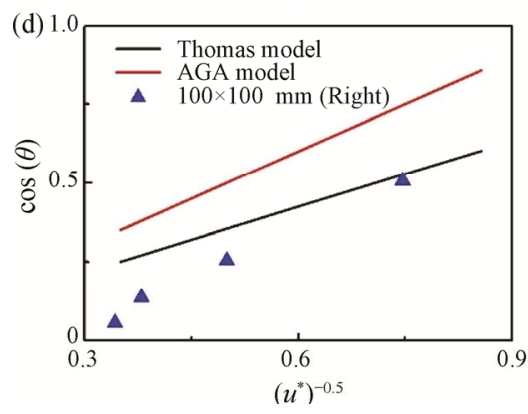

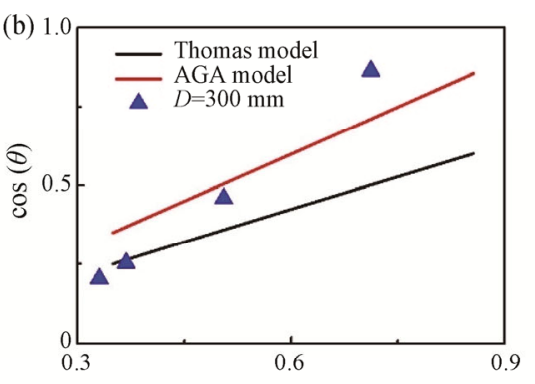

$\left(u^{*}\right)^{-0.5}$

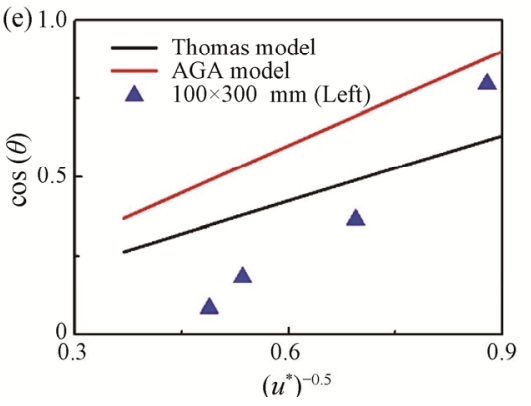

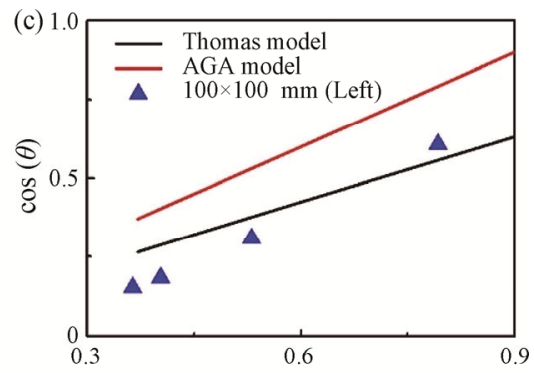

$\left(u^{*}\right)^{-0.5}$

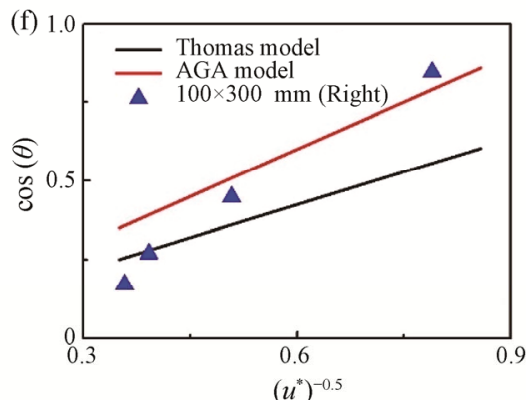

Fig. 8 Comparison of the experiment results with predicting model for flame tilting angle

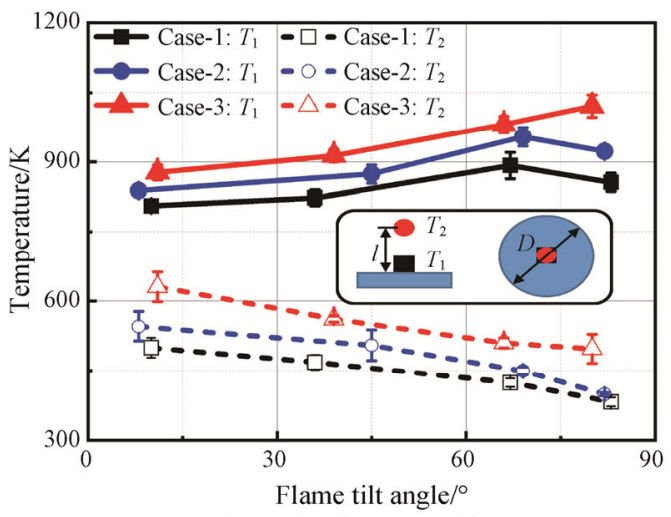

(a) Circle single pool fire

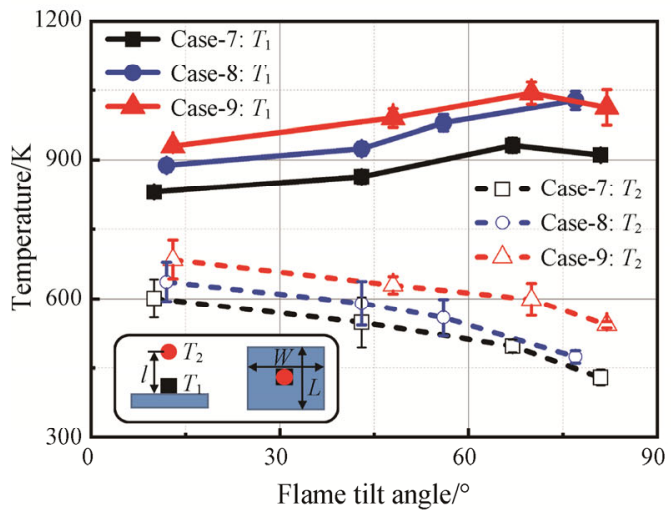

(c) Rectangle single pool fire

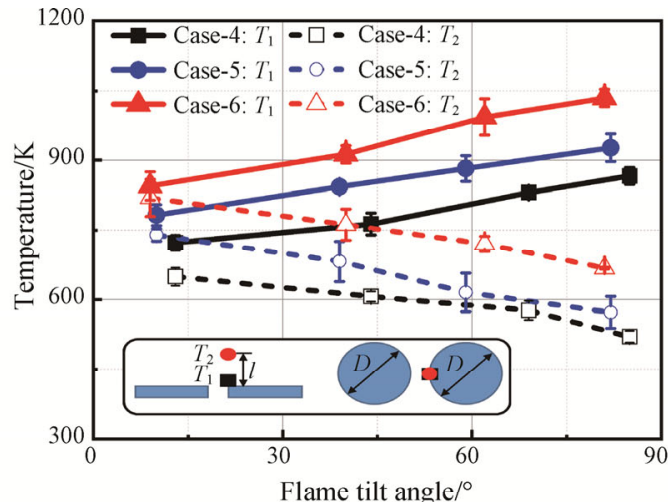

(b) Circle multiple pool fire

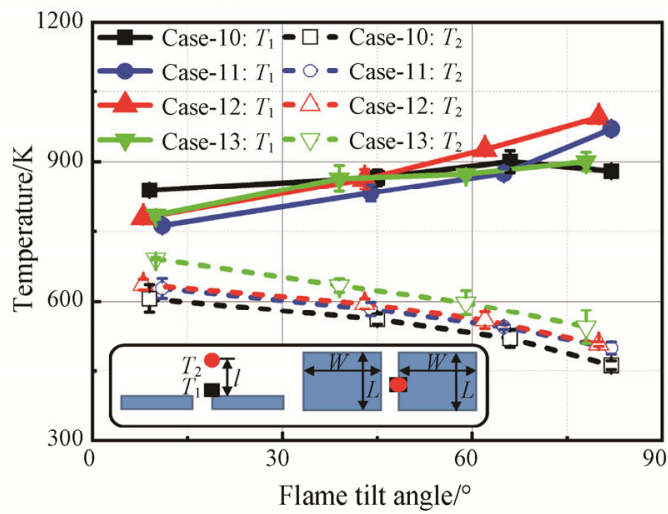

(d) Rectangle multiple pool fire

Fig. 9 Average temperature and flame tilt angle for pool fire

$T_{1}$ point for single/multiple pool fire basically increase with flame tilt increase, while the $T_{2}$ temperatures decrease as the $\theta$ increases, as shown in Fig. 9(c) and (d), which is similar to the circle pool fire. It is because that the $T_{2}$ point is mainly used to monitor the temperature of flame plume, for which the blowing flame tilt has a definite effect. As to $T_{2}$ point, it is closed to the fuel surface. When increasing the cross wind speed, the 
combustion rate and temperature will enhance. In addition, the temperature profile of Case-10, Case-11, Case-12 and Case-13 is relatively closed, compared with other cases.

\section{Conclusions}

Based on kerosene pool fire, the flame morphology and combustion characterization was investigated in this work. A series of experimental cases were carried out, including single pool fire and multiple pool fire, circle fuel pan and rectangle fuel pan with various dimensions. According to the results, some conclusions can be inferred as follows:

(1) The average burning rate of single pool fire can be consistent with current prediction method very well. However, it is not suitable for multiple pool fire, which could be influenced by heat back from adjacent pool fire.

(2) The flame tilt angle increases as cross wind speed increases, which can be predicted by previous Thomas and AGA model. In addition, it can be found that the tilt angle of left flame is larger than that of right flame for multiple pool fire.

(3) The temperature above the fuel surface $\left(T_{1}\right)$ increases with wind speed, while the temperature of flame plume $\left(T_{2}\right)$ decrease as wind speed increases. In addition, $T_{1}$ is larger than $T_{2}$ for different cases.

\section{Acknowledgment}

This work is supported by the National Natural Science Foundation of China (Grant No. 51736010).

\section{References}

[1] Jujuly M.M., Rahman A., Ahmed S., Khan F., LNG pool fire simulation for domino effect analysis. Reliability Engineering \& System Safety, 2015, 143: 19-29.

[2] Yang Y., Chen G., Chen P., The probability prediction method of domino effect triggered by lightning in chemical tank farm. Process Safety and Environmental Protection, 2018, 116: 106-114.

[3] Wu D., Chen Z., Quantitative risk assessment of fire accidents of large-scale oil tanks triggered by lightning. Engineering Failure Analysis, 2016, 63: 172-181.

[4] Vasanth S., Tauseef S., Abbasi T., Abbasi S., Multiple pool fires: occurrence, simulation, modeling and management. Journal of Loss Prevention in the Process Industries, 2014, 29: 103-121.

[5] Bariha N., Srivastava V.C., Mishra I.M., Theoretical and experimental studies on hazard analysis of $\mathrm{LPG} / \mathrm{LNG}$ release: a review. Reviews in Chemical Engineering, 2017, 33: 387-432.
[6] Munoz M., Planas E., Ferrero F., Casal J., Predicting the emissive power of hydrocarbon pool fires. Journal of Hazardous Materials, 2007, 144: 725-729.

[7] Zhang S., Zhang Q., Influence of geometrical shapes on unconfined vapor cloud explosion. Journal of Loss Prevention in the Process Industries, 2018, 52: 29-39.

[8] Birk A.M., Shock waves and condensation clouds from industrial BLEVEs and VCEs. Process Safety and Environmental Protection, 2017, 110: 15-20.

[9] Alileche N., Olivier D., Estel L., Cozzani V., Analysis of domino effect in the process industry using the event tree method. Safety Science, 2017, 97: 10-19.

[10] Cozzani V., Campedel M., Renni E., Krausmann E., Industrial accidents triggered by flood events: analysis of past accidents. Journal of Hazardous Materials, 2010, 175: 501-509.

[11] Liu Z., Carpenter D., Kim A.K., Characteristics of large cooking oil pool fires and their extinguishment by water mist. Journal of Loss Prevention in the Process Industries, 2006, 19: 516-526.

[12] Sudheer S., Kumar L., Manjunath B., Pasi A., Meenakshi G., Prabhu S., Fire safety distances for open pool fires. Infrared Physics \& Technology, 2013, 61: 265-273.

[13] Koseki H., Large scale pool fires: results of recent experiments. Fire Safety Science, 2000, 6: 115-132.

[14] $\mathrm{Hu}$ L., A review of physics and correlations of pool fire behaviour in wind and future challenges. Fire Safety Journal, 2017, 91: 41-55.

[15] Sun H., Wang C., Liu H., Li M., Zhang A., Zhao W., et al., Experimental study of combustion characteristics of circular ring thin-layer pool fire. Energy \& Fuels, 2017, 31: 10082-10092.

[16] Chatris J., Quintela J., Folch J., Planas E., Arnaldos J., Casal J., Experimental study of burning rate in hydrocarbon pool fires. Combustion and Flame, 2001, 126: $1373-1383$.

[17] Hu L., Kuang C., Zhong X., Ren F., Zhang X., Ding H., An experimental study on burning rate and flame tilt of optical-thin heptane pool fires in cross flows. Proceedings of the Combustion Institute, 2017, 36: 3089-3096.

[18] Ferrero F., Munoz M., Arnaldos J., Effects of thin-layer boilover on flame geometry and dynamics in large hydrocarbon pool fires. Fuel Processing Technology, 2007, 88: 227-235.

[19] Hu L., Wu L., Liu S., Flame length elongation behavior of medium hydrocarbon pool fires in cross air flow. Fuel, 2013, 111: 613-620.

[20] Tang F., Zhu K., Dong M., Shi Q., Mean flame height and radiative heat flux characteristic of medium scale rectangular thermal buoyancy source with different aspect ratios in a sub-atmospheric pressure. International Journal of Heat and Mass Transfer, 2015, 84: 427-432.

[21] Muñoz M., Arnaldos J., Casal J., Planas E., Analysis of 
the geometric and radiative characteristics of hydrocarbon pool fires. Combustion and Flame, 2004, 139: 263-277.

[22] Zhang X., Hu L., Zhu W., Zhang X., Yang L., Axial temperature profile in buoyant plume of rectangular source fuel jet fire in normal-and a sub-atmospheric pressure. Fuel, 2014, 134: 455-459.

[23] Kearney S.P., Grasser T.W., Laser-diagnostic mapping of temperature and soot statistics in a 2-m diameter turbulent pool fire. Combustion and Flame, 2017, 186: 32-44.

[24] Mudan K.S., Thermal radiation hazards from hydrocarbon pool fires. Progress in Energy and Combustion Science, 1984, 10: 59-80.

[25] Varshavskii G.A.., Germeier E.N., Diffusion theory of liquid hydrogen burning. Combustion, Explosion, and Shock Waves, 1967, 3: 236-241.

[26] Heskestad G., Luminous heights of turbulent diffusion flames. Fire Safety Journal, 1983, 5: 103-108.

[27] Moorhouse J., Scaling criteria for pool fires derived from large-scale experiments. European Federation of Chemical Engineering. 1982, 71: 165-179.

[28] Hu L., Liu S., de Ris J.L., Wu L., A new mathematical quantification of wind-blown flame tilt angle of hydrocarbon pool fires with a new global correlation model. Fuel, 2013, 106: 730-736.

[29] Lam C.S., Weckman E.J., Wind-blown pool fire, Part I: Experimental characterization of the thermal field. Fire Safety Journal, 2015, 75: 1-13.

[30] Lam C.S., Weckman E.J., Wind-blown pool fire, Part II: Comparison of measured flame geometry with semiempirical correlations. Fire Safety Journal, 2015, 78:
$130-141$

[31] $\mathrm{Hu} \mathrm{L.,} \mathrm{Liu} \mathrm{S.,} \mathrm{Wu} \mathrm{L.,} \mathrm{Flame} \mathrm{radiation} \mathrm{feedback} \mathrm{to} \mathrm{fuel}$ surface in medium ethanol and heptane pool fires with cross air flow. Combustion and Flame, 2013, 160: 295306.

[32] Planas-Cuchi E., Casal J., Flame temperature distribution in a pool-fire. Journal of Hazardous Materials, 1998, 62: 231-241.

[33] Fukuda M., Characteristics of two small pool fires arranged two different horizontal planes. Proceedings of the 5th Asia-Pacific Conference on Combusion, 2005, pp. 281-284.

[34] Delichatsios M.A., A correlation for the flame height in "Group" fires. Fire Science and Technology, 2007, 26: $1-8$.

[35] Vasanth S., Tauseef S., Abbasi T., Abbasi S., Simulation of multiple pool fires involving two different fuels. Journal of Loss Prevention in the Process Industries, 2017, 48: 289-296.

[36] Steinhaus T., Welch S., Carvel R.O., Torero J.L., Large-scale pool fires. Thermal Science, 2007, 11: 101-118.

[37] Babrauskas V., Estimating large pool fire burning rates. Fire Technology, 1983, 19: 251-261.

[38] Thomas P., The size of flames from natural fires. Symposium (International) on Combustion, 1963, 9(1): 844-859.

[39] Beyler C.L., Fire hazard calculations for large, open hydrocarbon fires. In: Hurley M.J. et al. (eds) SFPE Handbook of Fire Protection Engineering, Springer, New York, NY, 2016: 2591-2663.

DOI: https://doi.org/10.1007/978-1-4939-2565-0_66. 